\title{
(Re)Configurações identitárias do professor coordenador de ingles sob a luz da avaliatividade
}

Identity (re)configurations by the Head of the English department in the light of evaluation

Célia Elisa Alves de Magalhães Pontifícia Universidade Católica do Rio de Janeiro Adriana Nogueira Accioly Nóbrega Pontifícia Universidade Católica do Rio de Janeiro

Resumo: Desenvolvido na área da Linguística Aplicada das Profissões (SARANGI, 2012), este trabalho investiga a construção identitária do professor coordenador de inglês, com base em elementos avaliativos. A arquitetura teórica fundamenta-se no conceito de identidade pelo viés de teorias socioconstrucionistas (BUCHOLTZ; HALL, 2003, 2005) em interface com os pressupostos do Sistema de Avaliatividade (MARTIN; WHITE, 2005; VIAN JR., 2009, 2012). Os dados da pesquisa foram gerados por meio de entrevista de pesquisa qualitativa e os resultados sugerem que a (re)configuração identitária do professor coordenador, neste contexto, perpassa pelo uso de recursos semânticos avaliativos de afeto, julgamento e apreciação.

Palavras-chave: Identidade. Avaliação. Professor coordenador de inglês.

Abstract: Developed in the field of Applied Linguistics and Professional Practice (SARANGI, 2012), this work investigates the construction of the identity of the Head of the English Department with focus on evaluation. The theoretical framework is the concept of identity according to the social constructionist theories (BUCHOLTZ; HALL, 2003, 2005) in interface with the Appraisal Theory (MARTIN; WHITE 2005; VIAN JR., 2009, 2012). Data was gathered through a qualitative research interview and results suggest that the use 
of evaluative and semantic resources of affect, judgment and appreciation permeate the identity (re)configuration of the Head in the target context.

Key-words: Identity. Evaluation. Head of the English Department

\section{Introdução}

Adriana Nogueira Accioly Nóbrega

Célia Elisa Alves de Magalhães

A função de professor coordenador de inglês tem encontrado, de forma crescente, espaço profissional em diferentes instituições educacionais, tais como cursos de idiomas, escolas, faculdades e universidades. Resumidamente, podemos definir o professor coordenador de inglês como um docente que está na posição de coordenador. Entretanto, as atribuições do professor coordenador ainda não estão claramente delineadas. Por um lado, suas funções estariam ligadas ao fazer pedagógico, enquanto que, por outro, sua atuação iria além do caráter didático e estaria relacionada não só a questões burocráticas e administrativas como também a aspectos disciplinares. Na dimensão profissional ocupada pelo professor coordenador de inglês, doravante também PCI, verifica-se também uma diversidade de identidades inseridas no espaço complexo e dinâmico que é a instituição educacional.

Diante desse quadro, o presente trabalho, que se insere na área da Linguística Aplicada das Profissões (SARANGI, 2012) visa investigar a construção identitária do PCI com base nas percepções dos participantes deste estudo, a saber, três professores de inglês e uma PCI de duas escolas de educação infantil, ensino fundamental e médio da rede de ensino privada do Rio de Janeiro, realçando a contribuição de elementos avaliativos presentes na prática discursiva gerada no contexto da entrevista de pesquisa qualitativa.

Para tanto, a arquitetura teórica deste estudo fundamenta-se no conceito de identidade proposto pelo viés de teorias do socioconstrucionismo (BUCHOLTZ; HALL 2003, 2005), que entendem a(s) identidade(s) como um processo histórico e social construído no discurso. Embora existam estudos envolvendo tanto a construção identitária de professores de inglês (FABRICIO; BASTOS, 2009; JOHNSON, 2006) quanto reflexões acerca do trabalho e atuação do coordenador em instituições educacionais, como o coordenador pedagógico (DOMINGUES, 2009; OLIVEIRA, 2009), esta pesquisa mostra-se significativa e assume contornos mais específicos a partir do enfoque na construção identitária do professor coordenador da disciplina de língua inglesa. Em interface com os estudos de identidade, baseamo-nos também nas contribuições da Linguística Sistêmico-Funcio- 
nal, (HALLIDAY, 1994; HALLIDAY; MATHIESSEN, 2004) para a análise da construção das identidades do PCI, mais especificamente do subsistema de Atitude $^{1}$ do Sistema de Avaliatividade (MARTIN; WHITE, 2005; VIAN JR; 2009, 2012; VIAN JR et al., 2010), para a análise dos recursos semânticos de valores. Enquanto a Linguística Sistêmico-Funcional, doravante também LSF, preocupa-se com os aspectos gramaticais da linguagem, o Sistema de Avaliatividade volta-se à análise do aspecto discursivo, tendo como foco o estrato semântico discursivo da linguagem.

Acreditando que é possível "estudar temas sociais por meio da linguagem, enfocando os itens avaliativos dos textos" (FREITAS, 2010, p. 247), empregamos os recursos propostos pelo Sistema de Avaliatividade na análise dos dados e sugerimos que os recursos semânticos de valores podem revelar facetas da construção das identidades do PCI no contex-

(Re)Configurações identitárias do professor coordenador de inglês sob a luz da avaliatividade to da pesquisa em questão. Desse modo, podemos dizer que a relevância deste trabalho consiste em sua contribuição para a reflexão sobre os modos de agir e as funções desempenhadas pelo PCI, bem como para a investigação acerca da (re)configuração de suas múltiplas identidades, a partir da forma como os participantes constroem seus discursos.

\section{A questão identitária: fenômeno sociocultural e discursivo}

Os estudos acerca da construção de identidades têm associado os processos identitários às práticas discursivas (SHIFFRIN, 1996; MISHLER, 1999; FABRICIO; BASTOS, 2009; MOITA LOPES, 2002). Em alinhamento com essa reflexão contemporânea, Moita Lopes (2003, p. 19) propõe que a temática da questão identitária está relacionada à concepção de linguagem como discurso, isto é, "uma concepção que coloca como central o fato de que todo uso da linguagem envolve ação humana em relação a alguém em um contexto interacional específico". O autor observa que todo discurso origina-se de alguém cujas marcas identitárias o localizam na vida social e o posicionam no discurso de modo singular assim como seus interlocutores. Dessa forma a dinâmica identitária não pode ser considerada um processo estanque, ou seja, a identidade "não é um produto acabado" (BHABHA, 1994, p. 51).

Em suma, de acordo com a concepção socioconstrucionista so-

1. Segundo os fundamentos do Sistema de Avaliatividade, "as letras maiúsculas na Gramática Sistêmico-Funcional são usadas para referência ao plano do sistema, em oposição ao plano da atualização concreta (num texto, por exemplo) das possibilidades sistêmicas." (BALOCCO, 2009, p.41). 
Adriana Nogueira Accioly Nóbrega

Célia Elisa Alves de Magalhães

bre as identidades, aprendemos a ser quem somos nas práticas discursivas em que nos engajamos com outros "e que têm, portanto, uma base sócio-histórica e cultural" (MOITA LOPES, 2003, p. 25). No caso deste estudo, a construção identitária do PCI também é situada em contextos sócio-históricos e culturais (MAGALHÃES, 2013). Consequentemente, seu processo identitário pode ser entendido como uma construção social marcada, entre outros fatores, por aspectos relacionados à sua história de vida pessoal, às suas funções e rotina nos espaços educacionais, à história da educação, bem como aos discursos que circulam no contexto sociocultural sobre esse profissional. Em consonância com a visão do processo identitário como um construto de natureza social formado em práticas discursivas, Bucholtz e Hall $(2003,2005)$ sugerem que a identidade é construída intersubjetivamente por meio de relações conhecidas como táticas de intersubjetividade.

As táticas de intersubjetividade dividem-se em três processos distintos. 0 primeiro deles, chamado de adequação/distinção, refere-se aos meios pelos quais os falantes constroem similaridade e diferença. Para que os indivíduos sejam incluídos ou não em um determinado grupo, eles não precisam apresentar uma identificação total; isto é, a observação de alguma similaridade pode ser suficiente para definir o pertencimento a um determinado grupo, de acordo com o propósito interacional do momento. Desse modo, as diferenças são minimizadas. O segundo processo, autenticação/desnaturalização, corresponde aos modos que permitem aos falantes construir genuinidade/artificialidade. Nesse caso, os falantes podem reivindicar, discursivamente, a veracidade ou a artificialidade de atributos para a construção identitária. Finalmente, o terceiro processo, ou seja, a autorização/ilegitimação, diz respeito às maneiras nas quais os falantes constroem autoridade/ilegitimação. A autorização considera a afirmação/imposição de uma identidade por meio de estruturas institucionalizadas de poder/ideologia; enquanto que a ilegitimação relaciona-se ao modo como as identidades são censuradas ou ignoradas por essas mesmas estruturas. Em outras palavras, esse processo mostra que as identidades podem ser legitimadas, ou não, através das identidades institucionais, que representam estruturas de poder e de ideologia.

\section{A construção identitária sob a luz da Avaliatividade}


Alicerçado em uma perspectiva socioconstrucionista da dinâmica identitária, este trabalho lança mão de construtos da LSF, mais especificamente do Sistema de Avaliatividade (MARTIN, 2003; MARTIN; WHITE, 2005; VIAN JR et al., 2010), para a sua investigação sobre a construção de identidades (NÓBREGA; MAGALHÃES, 2012).

A LSF propõe a noção de linguagem sob uma perspectiva sociossemiótica (HALLIDAY; HASAN, 1989), isto é, investiga a linguagem como um sistema utilizado para criar significados em diferentes interações sociais. De acordo com o proposto pela LSF (HALLIDAY, 1994; HALLIDAY; MATTHIESSEN, 2004), existem significados de três naturezas que estão centrados nos usos que fazemos da linguagem, a saber: usamos a linguagem para falar de nossa experiência sobre o mundo (significado ideacional), para estabelecer e manter relações sociais (significado interpessoal), e para organizar nossas mensagens e relacioná-las com outras mensagens (significado textual). É por intermédio de três metafunções que os significados irão se realizar léxico-gramaticalmente: metafunção ideacional, metafunção interpessoal e metafunção textual. A primeira se relaciona à maneira como representamos o mundo e nossas experiências; a segunda diz respeito às trocas sociais, ilustrando o posicionamento e envolvimento do falante em seu discurso e de outros participantes da interação; a última organiza a mensagem como texto, dando forma às duas metafunções anteriores. Tanto os significados quanto as metafunções centram-se em contextos situacionais específicos e estão interligados e superpostos, fazendo com que a linguagem se configure como um modelo multidimensional.

Na proposta da LSF, a linguagem é dividida em três estratos grafo-fonológico, léxico-gramatical e semântico-discursivo - realizações dos contextos de cultura e de situação e, como proposto por Martin e Rose (2003, p. 4), na LSF, “a análise do discurso é realizada em interface com a análise da gramática e a análise da atividade social", conferindo à teoria sistêmico-funcional o seu foco de análise do discurso: "além da oração, em recursos semânticos que nos levam de uma oração à outra, enquanto o texto se desdobra." (op. cit. 2003, p. 1).

Seis sistemas compõem a semântica do discurso: (i) Ideação; (ii) Conjunção; (iii) Identificação; (iv) Periodicidade; (v) Negociação; (vi) Avaliatividade (MARTIN; ROSE, 2003, p. 17; VIAN JR., 2012, p. 109). Assim como ocorre com as metafunções no nível léxico-gramatical, os seis sistemas componentes do nível discursivo estão interligados e interde- 
Adriana Nogueira Accioly Nóbrega

Célia Elisa Alves de Magalhães

pendentes, sendo sua separação realizada apenas para fins de análise, visto que ao focarmos em um dos sistemas os demais não deixam de existir, "pois isso feriria o princípio metafuncional da linguagem base da teoria hallidayana." (VIAN JR, 2012, p. 109).

Neste trabalho, para a investigação da construção das identidades do PCI, nos fundamentamos no Sistema de Avaliatividade, que está inserido na metafunção interpessoal. O Sistema de Avaliatividade contempla um recurso específico da linguagem, a avaliação, que possibilita a análise sobre o modo pelo qual o escritor/falante, a partir de uma gama de opções do sistema linguístico, posiciona-se no discurso ao expressar sua opinião e sentimentos, como também ao emitir comentários sobre suas percepções de mundo. Como afirma Nóbrega (2009, p. 90), o Sistema de Avaliatividade pode ser definido como "uma perspectiva de análise textual, situando-se no campo da avaliação das atividades interpessoais, no nível da semântica do discurso", sendo, portanto, um significativo aporte teórico para a reflexão sobre a construção de identidades que emergem no discurso.

o Sistema de Avaliatividade divide-se em três subsistemas inter-relacionados: Atitude, foco do recorte de pesquisa proposto neste artigo, Engajamento e Gradação². De acordo com Martin e Rose (2003), a Atitude diz respeito aos nossos sentimentos, à ética e à estética e fornece recursos para avaliar emoções, comportamentos e coisas, encontrando-se dividido em três campos semânticos: afeto, julgamento e apreciação. Mesmo possuindo características próprias, todos estão no domínio dos sentimentos e, consequentemente, interligados pelo afeto (MARTIN, 2003, p. 147). Tanto o afeto quanto o julgamento e a apreciação podem revelar-se no texto verbal ou não-verbal de forma implícita ou explícita, podendo também expressar avaliações semânticas positivas ou negativas (op.cit., p. 142).

O primeiro campo semântico, o afeto (MARTIN, 2003, p. 148-155), que está centrado no avaliador, ou seja, no falante/escritor, relaciona-se às avaliações sobre emoções e classifica-se em três categorias de análise: felicidade/infelicidade; segurança/insegurança; e satisfação/ insatisfação. Quando o afeto é expresso em primeira pessoa, denomina-se autoral; e quando expresso em segunda ou terceira pessoa, recebe o nome de não autoral. Em termos lexicais, o afeto pode realizar-se por intermédio de verbos de emoção como "gostar" e "odiar"; de advérbios, especialmente de modo, como "infelizmente"; de adjetivos como "tris- 
te" e "alegre"; de substantivos como "tristeza" e "alegria". No entanto, a tentativa de categorização léxico-gramatical proposta pelo Sistema de Avaliatividade, como aponta Nóbrega (2009, p.95), é meramente ilustrativa. A interpretação dos recursos avaliativos baseia-se na totalidade do texto e no sistema de crenças que o ouvinte/leitor traz para a interpretação, e não somente em uma palavra (WHITE ([2001] 2015).

O segundo campo semântico, o julgamento, afasta-se da perspectiva do avaliador e passa à perspectiva do avaliado, estando associado à avaliação moral e ética do comportamento humano (MARTIN, 2003, p. 155-159) ou das normas sociais, envolvendo posicionamentos como "elogiar" ou "criticar" atos, crenças e valores. O julgamento pode ser subdividido em dois tipos: estima social e sanção social (MARTIN, 2003, p. 156). A estima social envolve admiração e crítica sem implicações le-

(Re)Configurações identitárias do professor coordenador de inglês sob a luz da avaliatividade gais, porém com avaliações que podem rebaixar a estima das pessoas em sua comunidade; relaciona-se à normalidade (o quão normal alguém é), à capacidade (o quão capaz alguém é) e à tenacidade (o quão decidido ou firme alguém é). A sanção social envolve elogios e censuras com implicações legais e está associada à veracidade (o quão confiável alguém é) e à conduta (o quão ético alguém é).

Por fim, a apreciação, terceiro campo semântico do subsistema de Atitude (MARTIN, 2003, p. 159-161), está vinculada à avaliação da aparência ou estética de objetos, processos, fenômenos naturais e situações. Este subsistema encontra-se organizado segundo três variáveis: reação, composição e valor (MARTIN, 2003, p. 160). Nóbrega (2009, p. 99) sugere os seguintes questionamentos para avaliar cada uma dessas variáveis: "o quão bom/ruim você acha que isto é?" (reação); "como você acha que ficou o todo, a composição de partes?" (composição); “como você julga/entende isto?” (valor).

\section{Contextualização da pesquisa}

Esta pesquisa qualitativa-interpretativa (DENZIN; LINCOLN, 2006), recorte de um estudo de cunho etnográfico (ANDRÉ, 2001) realizado no período de 2011 a 2012, utilizou a entrevista qualitativa de pesquisa do tipo semiestruturado (GASKELL, 2007) para a geração dos dados. Neste trabalho, a entrevista de pesquisa é considerada um "evento de fala" moldado por respostas a perguntas em uma (co)construção entre entrevistado e entrevistador sobre o que falam um para o outro (MISHLER, 1986).

A instituição onde ocorreu a pesquisa recebeu, por questões éti- 
Adriana Nogueira Accioly Nóbrega

Célia Elisa Alves de Magalhães

cas, o nome fictício de Colégio Brasil. Pela mesma razão, todos os outros nomes, locais e informações que pudessem identificar a instituição locus da pesquisa e os participantes foram omitidos ou alterados. O Colégio Brasil pertence à Rede Particular de ensino do Rio de janeiro e oferece aulas para todos os ciclos de ensino, sendo as aulas de língua inglesa ministradas a partir do 5‥ ano do Ensino Fundamental. Os participantes da pesquisa, cujas idades encontram-se entre 29 e 48 anos, são os seguintes: Ana e Flávio, professores de inglês; a professora pesquisadora Célia (identificada nas entrevistas como pp), uma das autoras deste artigo; Gisele, professora e PCI no Colégio Brasil. Todos os participantes atuam como docentes na área de ensino de inglês há mais de 10 anos, tendo os três primeiros atuado também como PCIs em cursos de ensino de idiomas.

Foram realizadas vinte entrevistas, feitas com a utilização de um gravador de voz digital, nas dependências do Colégio Brasil no período de novembro de 2011 a dezembro de 2012, As entrevistas aconteceram sem agendamento prévio e em dias diferentes, em função do horário de trabalho dos participantes. Neste recorte, são utilizadas duas entrevistas feitas da seguinte forma: a primeira com os professores Ana e Flávio e a segunda com a PCI Gisele. As entrevistas tiveram a duração aproximada de 10 e 8 minutos, respectivamente, sendo que neste trabalho são usados somente alguns excertos. Algumas palavras e trechos estão destacados em negrito para facilitar a leitura da análise dos dados. As convenções de transcrição encontram-se em anexo.

Os elementos linguísticos estudados no presente trabalho foram selecionados manualmente a partir da leitura e análise das entrevistas, ouvidas várias vezes durante o processo, também manual, de transcrição. Analisamos a totalidade das orações no contexto sociointeracional pesquisado, voltando nosso olhar para elementos do estrato léxico-gramatical da LSF como verbos e advérbios que caracterizam processos e circunstâncias, respectivamente, bem como para adjetivos e substantivos ${ }^{3}$ que expressam emoções e fundamentam conclusões sobre as avaliações

\footnotetext{
3. Sob a ótica da LSF (BUTT et. al., 2001; HALLIDAY; MATHIESSEN, 2004), o estrato léxico-gramatical realiza-se por meio dos sistemas de tema e rema, modo e transitividade. 0 sistema de transitividade constrói significados pelo uso dos seguintes componentes: processos, participantes e circunstâncias, que analogicamente à gramática tradicional correspondem aos verbos, substantivos e advérbios, respectivamente. Os processos classificam-se em materiais (processos do 'fazer'), mentais (processos do 'sentir'), relacionais (processos que estabelecem relações), verbais (processos do 'dizer'), comportamentais (processos que expressão o comportamento humano) e existenciais (processos que identificam a existência). Embora a análise do sistema da transitividade não seja o foco deste trabalho, uma vez que nos baseamos na Avaliatividade, discutimos pontualmente o uso de alguns processos e elementos circunstanciais que podem auxiliar no entendimento da construção identitária do PCI neste estudo.
} 
feitas no subsistema do afeto, do julgamento e da apreciação. Algumas instâncias de modalidade verbal ${ }^{4}$ e de linguagem figurada construídas pelos participantes também são analisadas.

\section{Identidades emergentes:}

\section{visões por diferentes perspectivas}

A análise dos dados gerados encontra-se subdividida em duas partes. A primeira analisa a construção identitária do PCI a partir do discurso dos professores de inglês, enquanto a segunda realiza o mesmo trabalho, com enfoque no discurso da PCI da instituição locus de pesquisa.

\section{A visão dos professores:}

\section{identidade, pertencimento e relações de poder}

No excerto 1, apresentado a seguir, Ana e Flávio discutem as atribuições do PCI sob diferentes perspectivas, construindo suas identidades a partir de questões de afiliação ou pertencimento e das relações de poder. Destacamos que, nesta seção, utilizamos os termos "PCI" e "coordenador" de forma intercambiável com o propósito de enfocar as funções referentes à coordenação mais especificamente.

\section{Excerto 1}

pp $\quad$ o que que você acha...é: que é a figura do coordenador pra você? Qual é o pape:l? Qual é a atuação dele?

Ana 0 coordenador, ele é uma espécie de: orientador, né? Da equi:pe, ao mesmo tempo... sei lá um ponto de apoio, né? Quando você preci:sa quando você precisa esclarecer alguma dúvida ou quando você precisa é:. resolver um problema. Assim ( ) você, você costuma encontrar nele um lugar de apoio...

Em seu turno, Ana compara o PCI a uma espécie de orientador da equipe. Aqui o coordenador pode ser visto como aquele que dará instruções aos professores e que coordenará ou organizará os processos pedagógicos. Ana também traz à tona, porém com alguma incerteza (sei lá), a ideia do coordenador visto como um ponto de apoio ou um lugar de apoio, isto é, alguém que poderá oferecer ajuda ou suporte (emocional/

4. Segundo Wilson (2008, p. 75), a modalidade "pode ser entendida como o julgamento feito pelo falante a respeito das probabilidades, ou obrigações, relacionadas com o que está dizendo". 
Adriana Nogueira Accioly Nóbrega

Célia Elisa Alves de Magalhães profissional) em caso de dúvida ou de um problema. Para destacar essa ideia, Ana realiza uma avaliação a partir do campo semântico de julgamento, uma vez que suas escolhas lexicais ponto de apoio e lugar de apoio referem-se à "atuação", ou seja, ao "comportamento" do profissional em questão, mencionado na terceira pergunta motivadora: Qual é a atuação dele?. Em sua avaliação, Ana revela suas crenças e valores quanto à função do coordenador, ao criar seu julgamento de capacidade e tenacidade, ligando sua avaliação à estima social do coordenador.

Ana também faz uma avaliação do ato de coordenar ao referir-se ao coordenador como um lugar. Essa avaliação encontra-se, simultaneamente, no campo semântico do julgamento (enquanto "atuação" do coordenador) e da apreciação. A repetição do item lexical preci:sa, junto com o recurso avaliativo paralinguístico de alongamento de vogal, concede maior força à avaliação e enfatiza a função do coordenador como um apoio ao qual o professor pode recorrer em caso de dúvida ou problema. Nesse caso, o coordenador será alguém que irá esclarecer a dúvida ou resolver o problema. Ao utilizar o verbo esclarecer, Ana traz a ideia de alguém que trará luz à dúvida, que também é um problema a ser solucionado.

De acordo com o fragmento da fala de Ana, podemos inferir, nesse contexto, a construção das identidades do PCI a partir de suas funções, pois além de o PCI estar voltado para as tarefas de orientação da equipe, ele oferece apoio profissional ou pessoal. Na construção discursiva das identidades do PCI, Ana produz instâncias avaliativas de afeto; isto é, dos recursos que constroem na linguagem reações de emoções, o que pode ser indicado pela escolha da modalidade expressa no processo verbal "precisar" que, semanticamente, carrega a ideia de necessidade extrema, voltando-se à emoção presente na relação. Portanto, o verbo "precisar" utilizado por Ana mostra suas percepções em relação ao compromisso e à responsabilidade do PCI em ajudar seus coordenados quando estes apresentam dúvidas ou problemas. Também a caracterização do PCI como ponto e lugar de apoio revela a presença do afeto no discurso da professora, pois igualmente ilustra escolhas centradas nesse campo semântico-discursivo. Observamos, contudo, que Ana faz uso de momentos de afeto não-autoral, pois não se posiciona diretamente sobre seu discurso, trazendo sua interlocutora (ou mesmo outros participantes do contexto pedagógico), ao usar quatro vezes o pronome pessoal você. Com isso, Ana parece criar um maior envolvimento com 
sua interlocutora, (co)construindo a identidade do PCI. Ao não assumir explicitamente a responsabilidade sobre seu discurso, a professora parece buscar crenças e valores comuns.

\section{Excerto 2}

Flávio É de uma maneira geral. (A brincadeira que eu faço) coordenador funciona (como um) bom sargento porque tem lá os comandados, comanda, mas também é comandado. Eu acho que é uma função muito complicada (hoje em dia) é: Você literalmente tem que agradar gregos e troianos( ). E muitas vezes eu acho que o coordenador fica numa saia justa ( ). Ele sabe o que tem que ser feito. Ele sabe como tem que ser feito. Mas ele sabe ( ) que não vai ser feito. (...)

(Re)Configurações identitárias do professor coordenador de inglês sob a luz da avaliatividade

No trecho transcrito acima, ao utilizar a linguagem figurada (sargento, agradar a gregos e troianos, saia justa) e repetir três vezes a palavra "sabe", Flávio avalia as relações de poder hierárquico que constroem as identidades do PCI e ressalta que o coordenador sabe tudo sobre regras e relações de poder. Nesse sentido, primeiro, Flávio compara o coordenador a um sargento e os professores a seus comandados, o que revela uma relação de poder em exercício por parte do coordenador. Desse modo, Flávio realiza uma avaliação, com base no campo semântico de julgamento, acerca do comportamento do coordenador, apontando para uma relação de assimetria entre a sua própria figura e os professores.

Em seguida, Flávio argumenta que o coordenador está igualmente submetido aos poderes da autoridade institucional, pois também é comandado. Por isso, ele tem que agradar a todos, gregos e troianos, o que muitas vezes o coloca numa saia justa, ou seja, em uma situação delicada porque o coordenador sabe o que tem que ser feito e sabe como tem que ser feito. Ao mesmo tempo, ele sabe que o que tem que ser feito nãa vai ser feito. Nessa ocasião, Flávio volta a utilizar recursos avaliativos de julgamento, revelando a atuação, isto é, o comportamento, do coordenador como o que comanda e é comandado, o que ilustra a avaliação da tenacidade (ao comandar) e da capacidade (ao ser comandado) do coordenador.

As escolhas linguísticas de Flávio, centradas em um discurso de comando, demonstram que o coordenador é o que deve ser firme e decidido, como um sargento, bem como aquele que deve ser capaz de seguir regras e obedecer. Observa-se que o verbo "saber" qualifica 
Adriana Nogueira

Accioly Nóbrega

Célia Elisa Alves

de Magalhães

positivamente o PCI pelo conhecimento que possui sobre suas funções. $\mathrm{O}$ PCI conhece as regras e o modo como devem ser cobradas e obedecidas. Entretanto, ele reconhece que não necessariamente as regras serão cumpridas por todos, coordenador e coordenados. Cumpre ressaltar a mitigação contida na modalidade verbal presente em "acho", palavra que Flávio utiliza duas vezes neste excerto ao responder à pergunta da professora pesquisadora sobre o PCI. É possível inferir, então, que falar sobre o PCI e suas funções pode ser um assunto delicado para os professores, provavelmente devido a questões de poder hierárquico existente na relação docentes-coordenador.

\section{Excerto 3}

Ana ( ) Eu acho assim, que problemas aconte:cem. Até porque muitas vezes a gente:... traz pra, pra uma reunião, os problemas de sala de aula que a gente viveu. E só quem tá ali dentro da sala de aula, viVENdo esse problema ( ) consegue saber a in-ten-si-da-de da situação.

Flávio ( )

Ana Quem tá do lado de fora NEM sempre consegue saber essa intensidade. Nem sempre consegue ter tão clara a expectativa que a pessoa vá reagir como você reagiria. Mas isso nem sempre acontece porque a pessoa está fora do problema, né? Então, é algumas vezes, eu: senti que assim, algumas decisões foram tomadas de uma maneira não equivocada, mas não da maneira que eu esperava, mas eu acho que é em virtude disso porque estar dentro da sala de aula é vivenciar problemas, experiências que você não vivencia dentro de uma sala de coordenação.

Flávio É diferente, é diferente. Você tá é: atrás de uma mesa, é diferente de você estar, ali (no fronte). É diferente.

No excerto 3, Ana e Flávio apontam para um aspecto de diferença existente entre professores, aqueles que estão dentro da sala de aula, e o coordenador, aquele que está atrás de uma mesa, e que por isso não vivencia da mesma forma, ou na mesma in-ten-si-da-de - ênfase através da silabação da palavra para expressar uma avaliação da situação - os problemas e experiências que os professores vivem. Esse fato corrobora para a ideia de que a identidade, conforme sugerem Bucholtz e Hall (2003, 2005), é relacional e constitui-se por meio de processos de ade- 
quação/distinção, ou seja, inclusão e exclusão a partir das diferenças percebidas. A inclusão em um determinado grupo ou classe traz em si a exclusão daqueles que não fazem parte desse grupo.

Também é possível notar, no segmento em questão, que as avaliações de afeto permeiam o discurso dos participantes. Tais avaliações são reveladas a partir de determinada seleção de itens lexicais como o processo verbal sentir, usado aqui para uma avaliação negativa, simultaneamente no campo do julgamento, sobre algumas decisões tomadas pelo coordenador: É: algumas vezes, eu: senti que assim, algumas decisões foram tomadas não de uma maneira equivocada, mas não da maneira que eu esperava. A construção da forma como a de tomada de decisão foi realizada também chama a atenção (não de uma maneira equivocada, mas não da maneira que eu esperava), e leva à conclusão de que o PCI não necessariamente negocia ou constrói decisões com os seus coordenados, outra faceta da sua constituição identitária.

Neste excerto, Ana, assim como Flávio, lança mão da mitigação contida na modalidade verbal presente em "acho" para falar sobre o PCI e suas funções, o que reitera a ideia de que falar sobre o PCI e sua atuação pode ser um assunto delicado devido à questão de poder hierárquico característico da posição.

Após a análise dos três excertos, percebemos que o discurso de Ana e Flávio enfocam diferentes visões a respeito do PCI. Ana constrói as identidades do PCI centrando-se em aspectos associados às relações pessoais. Para ela, este profissional é um orientador, um ponto/lugar de apoio. Em contraposição, Flávio evidencia as relações de assimetria de poder ao construir as identidades do PCI fazendo uma analogia com a figura do sargento que tem os comandados, que comanda, mas que também é comandado. A partir de analogias pautadas na linguagem figurada, Ana e Flávio elaboram seus argumentos e avaliam as funções e atribuições do PCI (re)dimensionando o seu processo identitário pelo viés da questão da afiliação à um determinado grupo social. Portanto, por meio de processos adequação/distinção (BUCHOLTZ; HALL, 2003, 2005), professores e PCIs são alocados em diferentes grupos. Os professores, ou seja, os comandados, localizam-se em um grupo que está dentro da sala de aula, vivendo um problema. O PCI, que está do lado de fora, atrás de uma mesa, pertence ao grupo daqueles que comandam, que gerenciam em uma escala mais alta na posição hierárquica, mas que também estão submetidos ao comando da instituição. As expressões que indicam circunstância em relação a lugar do lado de fora e por 
Adriana Nogueira Accioly Nóbrega

Célia Elisa Alves de Magalhães trás de uma mesa também apresentam valor exclusivo, definido pelos papéis do coordenador com base em suas funções.

Concluímos, então, que, neste contexto, o PCI, embora muitas vezes continue atuando como professor em sala de aula, passa a ser visto pelos docentes como "um diferente". Nesse cenário, o PCI representa a identidade institucional quanto ao poder hierárquico, o que legitima sua construção de identidades por meio do processo de autorização/ilegitimação. A autorização considera a afirmação de uma identidade, nesse caso, a identidade do PCI, legitimada pelas instituições educacionais, que representam estruturas de poder e de ideologia e que comandam esse profissional.

Notamos também que, para os professores Ana e Flávio, participantes da entrevista realizada no contexto em questão, a construção das identidades do PCI é, na maioria das vezes, realizada com o uso de recursos avaliativos de julgamento, o que nos leva à possibilidade de entendimento de que, para os professores entrevistados, o professor na função de coordenação deve ser avaliado de acordo com sua atuação ética e moral, assim como em seus comportamentos e atitudes de capacidade e tenacidade. No entanto, a presença do afeto no discurso indica que esse campo semântico perpassa os demais, revelando que as emoções se fazem presentes na relação entre coordenador e professor.

\section{A visão do PCI: identidade multifacetada em construção}

Nos extratos de entrevista que se seguem, veremos como Gisele, a partir dos momentos avaliativos de suas atribuições na posição de coordenadora, (re)configura suas identidades de PCI que gerencia situações, processos e pessoas.

\section{Excerto 4}

pp O que é o coordenador? Qual o papel? Qual a função do coordenador de inglês?

Gisele O coordenador de inglês a meu ver... Qual a função dele básica? É: organizar todos os- os processos de uma maneira que eles fluam, que eles aconteçam dentro dos prazos. Acho que isso é o maior desafio. Cumprir os prazos lidando com uma equipe grande com diversas séries, diversos níveis e com os problemas paralelos, né? Problemas de logística, em volta. Então acho que isso é o grande desafio. Você cumprir 'deadlines', né? Cumprir prazos, ah organizando os processos, de 
acordo com as pendências paralelas que é a logística, uma grande equipe, pais, né? Responsáveis que estão sempre ali interferindo, alunos >que estão sempre dando pequenos problemas < no meio do processo. Então é assim. A gente apaga incêndio, né? Você tem mil incêndios pra apagar num curto período de tempo é: <e que você tem que cumprir aquele processo pra aquela 'deadline', >né? Então você tem um processo pra cumprir uma 'deadline' e chuvas e intempéries no meio do caminho. Esse é o desafio. É isso que acho que é o papel de um coordenador.

Fundamentando-se no foco temático sobre o papel do PCI, Gisele, que exerce a função de PCI na instituição locus de pesquisa, constrói as (Re)Configurações identitárias do professor coordenador de inglês sob a luz da avaliatividade identidades desse profissional a partir da construção das suas próprias identidades de coordenadora. Dessa forma, a construção de identidades ocorre a partir da soma das tarefas realizadas na rotina de trabalho no que tange às questões administrativas e burocráticas da escola, ao gerenciamento do tempo para cumprir prazos e à organização dos processos. Todas essas tarefas são permeadas pelo aspecto da gestão de pessoas (lidando com uma equipe grande, pais), o que também pode configurar-se como um problema a ser resolvido, principalmente no que diz respeito aos responsáveis e alunos (Responsáveis que estão sempre ali interferindo, alunos >que estão sempre dando pequenos problemas). Nesse sentido, Gisele expressa uma avaliação negativa de julgamento, do tipo estima social, a respeito do comportamento dos responsáveis e dos alunos de forma direta e assertiva, que é ilustrada no nível léxico-gramatical pela repetição de palavras tais como o advérbio sempre e do uso do verbo no gerúndio (interferindo, dando), reforçando a ideia de que essa situação é recorrente. Entretanto, Gisele modaliza sua afirmação ao referir-se aos problemas causados como pequenos, o que de certa maneira, contrasta com a ideia de apagar incêndios ou mil incêndios.

Gisele também constrói as identidades do PCI centrando-se nos problemas que aparecem em sua própria prática cotidiana como coordenadora. Para apresentar sua autoimagem de PCI a partir das suas funções e dos problemas encontrados, Gisele elabora seus argumentos pautada em recursos semânticos e linguísticos que são unidos pela forma como ela constrói uma coerência discursiva. Seu discurso encontra-se alicerçado por uma rede lexical edificada com a utilização da repetição 
Adriana Nogueira Accioly Nóbrega

Célia Elisa Alves de Magalhães de palavras, que auxiliam no estabelecimento de relações léxico-gramaticais, semânticas e pragmáticas. Tal conexão permite conceber o discurso apresentado como uma unidade significativa que elabora Gisele como uma PCI que possui habilidades semelhantes à de profissionais que atuam em situações de perigo, como os bombeiros (A gente apaga incêndio, né? Você tem mil incêndios pra apagar num curto período de tempo, Então você tem um processo pra cumprir uma 'deadline' e chuvas e intempéries no meio do caminho). Observamos que as avaliações de julgamento realizadas por Gisele parecem se voltar mais para a sanção social do que para a estima social, uma vez que a PCI constrói suas identidades quase que como a pessoa que evita implicações legais, ressaltando sua conduta confiável e ética.

Na edificação dessa unidade de significado, Gisele utiliza o item intensificador maior (o maior desafio) para avaliar a organização dos processos dentro dos prazos estabelecidos como o desafio principal. A seguir, Gisele inclui ainda os problemas paralelos, problemas de logística, que compõem o grande desafio, palavra que ela intensifica com sua escolha pelo atributo grande. Assim, Gisele expressa uma grande preocupação com o cumprimento de prazos. Tal preocupação evidencia-se mais enfaticamente por meio da repetição das seguintes palavras: cumprir e prazos/'deadlines', prazos em inglês.

As palavras que se referem aos problemas a serem resolvidos também são repetidas no discurso (problemas, três vezes; incêndio(s), duas vezes; pendências, duas vezes). Os itens lexicais chuvas e intempéries, embora sejam utilizados somente uma vez, também compõem a unidade de sentido que Gisele constrói, pois substituem semanticamente a palavra problema. Notamos também uma espécie de gradação semântica no léxico usado como referência aos problemas enfrentados: problemas paralelos, problemas de logística, pendências paralelas, pequenos problemas, incêndio, mil incêndios, chuvas, intempéries. A repetição dessas palavras reforça a avaliação, no campo semântico da apreciação (principalmente de reação e valor), que Gisele faz de seu trabalho; ou seja, uma posição em que há inúmeros problemas, dentre eles, a pressão para o cumprimento de prazos. Por fim, Gisele ratifica e conclui a resposta que construiu em função das primeiras perguntas de sua interlocutora (o que éo coordenador? Qual o papel? Qual a função do coordenador de inglês?): Esse é o desafio. É isso que acho que é o papel de um coordenador.

No excerto 5, transcrito a seguir, concluímos que, para Gisele, 
no referido contexto, o PCI seria, então, não só alguém que gerencia processos e pessoas como também alguém que precisa administrar situações solucionando problemas sérios, que podem ser comparados aos problemas surgidos em situações de risco como as enfrentadas por bombeiros que lutam para salvar vidas em situações adversas.

(Re)Configurações identitárias

\section{Excerto 5}

pp Você lembra de alguma situação mais séria que aconteceu lá? do professor coordenador

Gisele Eu já: >substituindo < uma professora, expulsei da sala o filho do: diretor da: parte de diretório de pais, o presidente do: diretório de pais. $\mathrm{E}$ assim que eu tirei ele de sala eu ouvi de todos os alunos a minha volta, <fiscais inspetores e professores> que eu seria demitida no dia seguinte. E: o pai me de inglês sob a luz da avaliatividade procurou e eu achei que era pra ser demitida e não. Ele me ouviu e ainda chamou a atenção do menino.>Então esse foi um problema < que eu realmente... sai aquele dia da escola achando: Eu não estarei mais aqui amanhã. Mas tudo foi tranquilo. Fora isso, eu tenho problemas sérios de alunos expulsos de sala. Ontem, muito aluno expulso de sala por indisciplina porque lá eles são muito arrogantes, né? E: mas eu consigo resolver com os alunos. Nunca precisei chamar pai. Raros são os casos que eu preciso ligar pra um pai pra fazer queixa de uma- de um adolescente. (...)

Neste trecho da entrevista, a PCI Gisele apresenta uma situação problema que aconteceu na outra escola em que trabalha, enquanto substituía uma professora: expulsei da sala o filho do diretor da parte de diretório de pais, o presidente do diretório de pais. Ao reconstruir uma experiência vivida na posição de professora, durante o período em que já atuava como PCI, Gisele promove a constituição de suas identidades docentes e, consequentemente da própria coordenação pedagógica, projetando certa similaridade entre as duas categorias de profissionais. Gisele também faz uma avaliação positiva de apreciação acerca da resolução da situação de conflito (Mas tudo foi tranquilo.), que foi diferente de sua avaliação inicial ao achar que seria demitida (... sai aquele dia da escola achando: "Eu não estarei mais aqui amanhã."). Todavia, a previsão não foi consumada, pois, segundo Gisele, o pai do aluno ouviu o que ela tinha a dizer e ainda chamou a atenção do menino). Gisele avalia a situação 
Adriana Nogueira

Accioly Nóbrega

Célia Elisa Alves de Magalhães ao pensar que seria demitida: Eu não estarei mais aqui amanhã, e conclui sua avaliação: Mas tudo foi tranquilo, fazendo outra avaliação positiva de apreciação sobre o desfecho da situação. Desse modo, Gisele também constrói sua autoimagem de PCI por intermédio do sentido da autonomia e da confiança em seu potencial. Informalmente, poderíamos dizer que Gisele "se banca" ou "se garante" na função de coordenadora

Gisele também acrescenta à sua avaliação o fato de que nessa outra escola ela consegue resolver os problemas de indisciplina dos alunos sem entrar em contato com os pais (Nunca precisei chamar pai.). A ausência dessa necessidade está ilustrada pelo advérbio "nunca", que expressa a circunstância temporal e pelo verbo "precisar". Contudo, a seguir, Gisele reformula sua fala, deixando evidente que tal situação, embora não seja frequente,

pra um pai pra fazer queixa de uma- de um adolescente.). Portanto, é possível concluirmos que, segundo Gisele, uma outra função do coordenador seria a de assegurar que os problemas de indisciplina dos alunos sejam resolvidos dentro da escola, sem a necessidade de intervenção dos responsáveis. Novamente, o PCI aparece como uma figura de autoridade e de comando no que tange ao saber resolver problemas e controlar situações.

\section{Excerto 6}

pp Como você se tornou coordenadora?

Gisele Por um total acaso. É: > precisava-se< de uma coordenadora no Colégio Brown e: a: Helena, que acho que você conhece, trabalhava comigo no-no- curso BAE, no departamento de tecnologia e ela disse, "Gisele, eu acho que você tem o perfil pra coordenadora, pra gerente. Não sei como o curso BAE não te aproveita numa filial. >Você é boa de matemática, disso daquilo<, < de lidar com o público>. Acho que você seria uma excelente gerente ou coordenadora. É: tenta lá no Colégio Brown porque é só ensino médio, acho que seria uma boa experiência." Eu fui, fiz a entrevista. Mario, que era o coordenador geral, gostou de cara e eu comecei. Já tô lá há sete anos. E a partir daí, quando pintou a vaga aqui, ele me ligou de imediato pra vir pra cá, né? E coincidentemente foi no mesmo dia que eu fui demitida do curso BAE, né? Deus fechou uma porta e abriu uma janela enorme, de varanda. E eu acabei vindo pra cá. A partir da pergunta (Como você se tornou coordenadora?), Gisele 
contextualiza uma situação que ocorreu Por um total acaso, a partir da necessidade de um PCI para o Colégio Brown. Logo no início de seu relato, Gisele introduz a personagem Helena, que também é conhecida de sua interlocutora, para reivindicar a veracidade dos atributos e eventos que serão mencionados: a Helena, que acho que você conhece.

Ao reconstruir o diálogo com Helena, Gisele avalia positivamente o seu potencial para atuar como coordenadora, mostrando que possui as habilidades e capacidades que uma instituição educacional esperaria encontrar em um PCI (Gisele, eu acho que você tem o perfil pra coordenadora, pra gerente). Com a avaliação por meio do afeto não autoral, pois a PCI usa o discurso de Helena para avaliar sua capacidade, a construção das identidades de Gisele como PCI revela-se no uso do substantivo perfil, que é enfatizado, de forma paralinguística, com o aumento do tom de (Re)Configurações identitárias do professor coordenador de inglês sob a luz da avaliatividade voz. Gisele prossegue sua narrativa enumerando, ainda a partir da voz do outro, as características que compõem o perfil esperado para o PCI; isto é, ser bom em matemática, em lidar com o público, etc., atributos que Gisele diz, alicerçada na voz de Helena, possuir. A apresentação de sua autoimagem de PCI continua sob a luz favorável ressaltada pelo atributo excelente no elogio de Helena: Acho que você seria uma excelente gerente ou coordenadora. Para atenuar a intensidade do elogio expresso com a opção do atributo excelente, Gisele usa a forma condicional do verbo ser (seria)

Gisele também introduz a opinião de Mario, outra pessoa que sua interlocutora também conhece, para construir sua imagem de PCI de forma positiva e, novamente, conferir, discursivamente, veracidade aos fatos mencionados, por meio do processo de autenticação/desnaturalização. Nessa avaliação, Gisele usa o verbo "gostar", uma escolha lexical relacionada ao campo semântico do afeto: Mario, que era o coordenador geral, gostou de cara e eu comecei. A seguir, Gisele interrompe seu relato e faz um julgamento positivo de seu desempenho como PCI no Colégio Brown, ao informar que está lá há sete anos e que também foi convidada, pelo próprio Mario, para exercer a função de PCI no Colégio Brasil.

Esse mesmo trecho do relato de Gisele: Já tô lá há sete anos. E a partir daí, quando pintou a vaga aqui, ele me ligou de imediato pra vir pra cá, introduz a questão do seu desligamento do curso BAE: E coincidentemente foi no mesmo dia que eu fui demitida do curso BAE, né? Gisele recorre ao poder divino para justificar o desligamento (Deus fechou uma porta) e, ao mesmo tempo, a sua contratação como PCI pelo Colégio Brasil, ava- 
liando positivamente o seu desempenho na coordenação e construindo as identidades de uma PCI competente. A satisfação de Gisele expressa em sua avaliação é destacada pelo uso do atributo "enorme" com ênfase prosódica.

\section{Considerações Finais}

Adriana Nogueira Accioly Nóbrega

Célia Elisa Alves de Magalhães

Este estudo teve como objetivo investigar a construção identitária do PCI, com foco na a análise de elementos avaliativos presentes no discurso dos participantes. No contexto pesquisado, é possível verificar que, no processo de construção identitária, os participantes da interação discursiva estabelecem negociações nas quais participam aspectos relacionados à história de vida pessoal bem com às condições e funções de trabalho. Nesse sentido, observamos que as identidades do PCI são construídas não só ao longo da sua trajetória profissional, mas também nas práticas discursivas que ocorrem nas relações cotidianas no interior das instituições educacionais. Por isso, é natural que seu discurso seja permeado por sentidos de compromissos e de responsabilidades burocráticas e administrativas relativas às suas funções na coordenação, como ocorre no discurso de Gisele, a PCI do Colégio Brasil. Desse modo, discutir as identidades do PCI torna-se necessário, na medida em que é relevante entender as relações de poder que permeiam as instituições educacionais específicas bem como as questões pertinentes a esses lugares sociais.

No âmbito deste estudo, os dados também indicam que as identidades do PCI emergem das expectativas que os "outros" (instituições, colegas de trabalho, alunos e pais) projetam sobre a sua figura, que se vê e que é vista como um elo, um mediador de tensões entre o corpo docente e os alunos/responsáveis. Consequentemente, quando incorpora a função de coordenador, assume outras identidades ligadas a seus atributos não só de conhecedor dos saberes pedagógicos, mas também de autoridade hierárquica.

Todavia, o PCI, profissional oriundo do corpo docente, continua sendo um professor. A docência não é um lugar do qual o PCI se despede para nunca mais retornar. Ao contrário, a docência é a essência do PCI, o ponto de partida para o caminho até a coordenação. Porém é um caminho também de volta ou voltas, isto é, de idas e vindas, um ciclo na vida desse profissional que muitas vezes é confundido com outros tipos de coordenadores que não pertencem à área da educação. As identidades docentes fazem parte das identidades multifacetadas do 
PCI, identidades que são constantemente reconstruídas no discurso e na vida cotidiana.

No que tange à análise do discurso dos participantes à luz do Sistema de Avaliatividade, percebemos que a construção identitária do PCI revela-se nas avaliações feitas, tanto pelos professores quanto pela própria PCI, nos campos da semântica discursiva - afeto, julgamento e apreciação, por meio de recursos semânticos e lexicais que permeiam a negociação de sentidos criados durante a interação social. o fato de um maior número de ocorrências de avaliação de julgamento se fazer presente nos trechos analisados sugere que, para os participantes do contexto investigado, as identidades do PCI são construídas com base em elementos de estima social, principalmente no que diz respeito ao comportamento, à conduta e à confiabilidade desse profissional.

(Re)Configurações identitárias do professor coordenador de inglês sob a luz da avaliatividade

Por fim, ressaltamos que, embora este trabalho não reflita de forma central sobre questões relativas à formação de professores, ele traz importantes contribuições para os docentes que almejam a posição de coordenador de disciplina ou de outro segmento na área de educação. Afinal, conforme discutido neste estudo, o professor coordenador é oriundo do corpo docente e, por isso, essencialmente um professor.

\section{Referências}

ANDRÉ, M. E. Etnografia da prática escolar. Campinas. Papirus, 2001.

BALOCCO, A. E. O sistema do engajamento aplicado a espaços opinativos na mídia escrita. In: VIAN JR, O. et al. A linguagem da avaliação em língua portuguesa: Estudos sistêmico-funcionais com base no Sistema de Avaliatividade. São Carlos: Pedro \& João Editores, 2010, p. 41-55.

BHABHA, H. K. The location of culture. London and New York: Routledge, 1994.

BUCHOLTZ, M.; HALL, K.. Language and identity. In: DURANTI, A. (Ed.). A companion to linguistic anthropology. Oxford, Basil Blackwell, 2003, p. 268-294. 
Identity and interaction: A sociocultural linguistic approach. Discourse studies, v.7, n. 4-5, p. 585-614, 2005.

BUTT, D. et al. Using Functional Grammar: An Explorer's Guide. Sydney: Macquarie University, 2001, p. 2-11.

Adriana Nogueira Accioly Nóbrega

Célia Elisa Alves de Magalhães
DENZIN, N. K.; LINCOLN, Y. S. O planejamento da pesquisa qualitativa: teorias e abordagens. Porto Alegre: Artmed, 2006.

DOMINGUES, I. 0 coordenador pedagogico e o desafio da formação contínua do docente na escola. 2009. 235f. Tese (Doutorado em Educação), Pontifícia Universidade Católica de São Paulo, São Paulo, 2009.

FABRICIO, B. F.; BASTOS, L. C. Narrativas e identidade de grupo: a memória como garantia do "nós" perante o "outro". In: PEREIRA, M. das G. D.; BASTOS, C. R. P.; PEREIRA, T. C. (orgs.) Discursos socioculturais em interação: Interfaces entre a narrativa, a conversação e a argumentação. Rio de Janeiro: Garamond, 2009, p. 39-66.

FREITAS, L. G. Migrantes goianos e cenários estrangeiros: uma análise discursiva à luz da Teoria da Valoração. RevLet - Revista Virtual de Letras. v. 2, n. 1, p. 246-263, 2010.

GASKELL, G.. Entrevistas individuais e grupais. In: GASKELL, G.; BAUER, M. W. Pesquisa qualitativa com texto, imagem e som: um manual prático. Petrópolis: Vozes, 2007, p. 64-89.

HALLIDAY, M. A. K. An introduction to functional grammar. London: Edward Arnold, [1985] 1994.

HALLIDAY, M. A.K.; MATTHIESSEN, C. M. I. M. Halliday's introduction to functional grammar. 4 ed. London: Hodder Arnold, 2004.

HALLIDAY, M. A.K.; HASAN, R. Language, context and text: aspects of language in a social-semiotic perspective. Oxford: Oxford University Press, 1989. 
JOHNSON, G. C. The discursive construction of teacher identities in a research interview. In: DE FINA, A. et al.. Discourse and identity. Cambridge: CUP, 2006, p. 213-232.

MAGALHÃES, C. E. A. Então me bateu um grande frio na barriga. (Re)ConfiguraEm cena, o professor coordenador de inglês: um estudo sobre identidade e avaliação. 2013. 236f. Dissertação de Mestrado - Mestrado Pontifícia Universidade Católica do Rio de Janeiro, Rio de Janeiro, 2013.

MARTIN, J. R. Beyond exchange: appraisal systems in English. In: HUSTON, Suzan; THOMPSON, G. (Eds.). Evaluation in text. Oxford: Oxford University Press, 2003, p. 142-175. ções identitárias do professor coordenador de inglês sob a luz da avaliatividade

MARTIN, J. R.; ROSE, D. Working with discourse: meaning beyond the clause. New York: Continuum, 2003.

MARTIN, J. R.; WHITE, P. The language of evaluation. Great Britain: Palgrave/ Macmillan, 2005.

MISHLER, E. G. Research interviewing: Context and narrative. USA: Harvard, 1986.

Storylines: craftartists' narratives of identity. Cambridge: Harvard, 1999.

MOITA LOPES, L. P. Identidades fragmentadas: a construção discursiva de raça, gênero e sexualidade em sala de aula. Campinas, SP: Mercado das Letras, v. 1, 2002.

Socioconstrucionismo: discurso e identidades sociais. In:

(Org.) Discurso de identidades, Campinas: Mercado de letras, 2003, p. 13-38.

NÓBREGA, A. N. Narrativas e avaliação no processo de construção do conhecimento pedagógico: abordagem sociocultural e sociossemiótica. 2009. 244p. Tese de Doutorado - Doutorado em Letras, Pontifícia Universidade Católica do Rio de Janeiro, Rio de Janeiro, 2009. 
Adriana Nogueira

Accioly Nóbrega

Célia Elisa Alves de Magalhães
. ; MAGALHÃES, C. E. A. Narrativa e identidade: Contribuições da avaliação no processo de (re-)construção identitária em sala de aula universitária. Veredas (UFJF), Juiz de Fora, v. 16, n.2, p. 68-84, 2012.

OLIVEIRA, J. C. Um estudo sobre o coordenador pedagógico: sua identidade, seu trabalho e formação continuada no cotidiano escolar. 2009. 223f. Dissertação de Mestrado - Mestrado em Educação, Pontifícia Universidade Católica do Rio de Janeiro, Rio de Janeiro, 2009.

SARANGI, S. Applied Linguistics and Professional Discourse Studies. Veredas, vol. 16, no. 1, p. 1-18, 2012.

SHIFFRIN, D. Narrative as self-portrait: sociolinguistic construction of identity. Language in Society, v. 2, n. 25, p. 167-203, 1996.

VIAN JR, O. O Sistema de Avaliatividade e os recursos para gradação em língua portuguesa: questões terminológicas e de instanciação. D.E.L.T.A., v. 25, n. 1, p. 99-129, 2009.

- O Sistema de Avaliatividade e a linguagem da avaliação. In: VIAN JR, O. et al. (orgs.). A linguagem da avaliação em língua portuguesa: estudos sistêmico-funcionais com base no Sistema de Avaliatividade. São Carlos: Pedro \& João Editores, 2010, p. 19-29.

. Avaliatividade, engajamento e valoração. D.E.L.T.A., v. 28, n. 1, p. 105-128, 2012.

WHITE, P. Appraisal homepage. Disponível em: <www.grammatics. com/appraisal>. [2001] 2015. Acesso em: 19 jun. 2015.

WILSON, C. D. R. J. Relações interpessoais em fórum de discussão online: a perspectiva sistêmico-funcional em práticas discursivas de ensino a distância. 2008 268f. Tese de Doutorado - Doutorado em Letras/Estudos da Linguagem, Pontifícia Universidade Católica do Rio de Janeiro, Rio de Janeiro, 2008. 
Anexo I: Convenções de transcrição

\begin{tabular}{|c|c|c|c|}
\hline$\ldots$ & pausa não medida & : ou :: & alongamentos \\
\hline, & $\begin{array}{c}\text { entonação de conti- } \\
\text { nuidade }\end{array}$ & $($ ) & $\begin{array}{c}\text { fala não compre- } \\
\text { endida }\end{array}$ \\
\hline$\cdot$ & $\begin{array}{c}\text { entonação descen- } \\
\text { dente ou final de } \\
\text { elocução }\end{array}$ & (palavra) & fala duvidosa \\
\hline $\boldsymbol{s}$ & entonação ascendente & $\mathbf{( . . . )}$ & trecho editado \\
\hline sublinhado & ênfase & "palavra" & fala relatada \\
\hline >palavra< & fala mais rápida & <palavra> & fala mais lenta \\
\hline----- & silabação & MAIÚscuLA & $\begin{array}{c}\text { fala em voz alta ou } \\
\text { muita ênfase }\end{array}$ \\
\hline
\end{tabular}

(Re)Configurações identitárias do professor coordenador de inglês sob a luz da avaliatividade

Convenções basedas nos estudos da Análise da Conversação (ATKINSON; HERITAGE,

1984; GAGO, 2002). 
